review committee for family medicine's faculty scholarly activity requirement.

The AFMRD benefits greatly from the active involvement of its members in various organizations and activities, including CERA. For the last 2 years, Dr Paul Crawford, program director at Nellis Family Medicine Residency in Las Vegas, Nevada, has served as the AFMRD liaison to CERA. Dr Wendy Barr, associate program director at the Greater Lawrence Family Health Center in Lawrence, Massachusetts, is the new liaison.

CERA covets proposals from program directors, yet a limited number of proposals are received from program directors because, for one reason, program directors find many questions in the CERA surveys lack relevance to their roles. This lack of relevance is also the reason the AFMRD is taking the initiative to assist program directors in developing CERA proposals.

Those of us who consider ourselves novices at educational research and survey design will appreciate that the AFMRD Board is partnering with several researchers familiar with the CERA process to offer program directors mentoring, feedback, and suggestions prior to submission to CERA. Interested AFMRD members will be connected with a mentor/reviewer by contacting Lynn Pickerel at afmrd@aafp.org.

CERA accepts program director proposals twice a year, but please do not wait until the deadline-plan now. Develop your research question and hypothesis and start on the path to getting relevant questions about residency education answered!

Stephen Scbultz, MD, FAAFP, Paul Crawford, MD, FAAFP, Natasha Bbuyan, MD, Gretchen M. Dickson, MD, MBA, FAAFP, James $W$. Jarvis, MD, FAAFP; Lisa Maxwell, MD, Michael Mazzone, $M D_{i}$ W. Fred Miser, MD, MA, FAAFP $P_{i}$ Karen Mitchell, MD, FAAFP; Todd Shaffer, MD, MBA, FAAFP

$\begin{array}{ll}\text { Porth American } & \text { From the North } \\ \text { RIMARY CARE } & \text { American Primary Care } \\ \text { RESEARCH GROUP } & \text { Research Group }\end{array}$

Ann Fam Med 2015;13:389-390. doi: 10.1370/afm.1830.

\section{EXPANDING NAPCRG'S LEADERSHIP CAPACITY}

Over the past 2 years, the North American Primary Care Research Group (NAPCRG) has undergone an intentional transformation of its leadership engagement and governance structure. NAPCRG's mission statement states "NAPCRG is committed to a nurturing, informative and inspiring environment for all mem- bers." One approach to meeting this commitment is to engage members in organizational activities, and specifically leadership activities. In March 2013, with this priority as a guide, Norman Oliver, MD, MA, chair of NAPCRG's Nominations Committee, set about developing goals to increase membership engagement and leadership capacity.

One recommendation approved by the Board of Directors was a policy modification changing the terms of all members of the board from 3 two-year terms to 2 two-year terms. Limiting the number of terms creates frequent turnover in leadership positions allowing more members to get more involved. The board also approved a change in the term for the president of NAPCRG from a 2-year term to a 3-year term-a year as vice president, president, and immediate past president. The Nominations Committee suggested that one of the best ways for members to get involved is to serve as members of committees. Potential leaders can be identified leaders through several mechanisms including signup sheets for leadership roles and committees at the NAPCRG Annual Meeting.

During the NAPCRG 2013 Annual Meeting in Ottawa, Ontario, members expressed concerns about a lack of transparency regarding elections to the NAPCRG Board of Directors. Traditionally, outgoing members nominated their replacements, rather than placing an open call for nominations. Concerns were also expressed about a lack of diversity in board and committee chair positions. The board asked Dr Oliver and the NAPCRG executive director to draft recommendations for a new, fair, and transparent process for soliciting nominations and electing members to the Board of Directors. In February 2014, the board adopted a diversity statement affirming its commitment of a diverse membership, leaders, meetings, programs, research, and employment. In addition, the Nominations Committee proposed a transparent nominations process with job descriptions for every position on the board, and a revamped nominations and elections process. The board sought additional feedback from members on the policy and delayed adoption of the new process until the board met in April of that year. On April 7, 2014, the NAPCRG Board of Directors approved an election process where board job descriptions and open positions are publicized to the membership the Nominations Committee reviews, screens, and prioritizes nominees based on the relevance of their qualifications; and finally the final slate of nominations are approved by the NAPCRG Board of Directors. NAPCRG is now in its second cycle of the transparent and open nominations and election process, resulting in positive feedback thus far.

Furthermore, in an effort to increase awareness of leadership opportunities within NAPCRG, a special 
session was held during the NAPCRG Annual Meeting in New York, NY on November 24, 2014. The goal of the session was to inspire and inform NAPCRG members about how to get more involved in the organization. The session provided an overview of NAPCRG's history, culture and personal testimonials from current and past leaders about the importance of the organization. Information was shared on how to get involved in special interest groups, committees, and the Board of Directors. The session was well attended and will be repeated at future Annual Meetings.

The final stage of the expansion of NAPCRG's leadership capacity is improvement to the committee and subcommittee structure. Historically, each committee chair determined who was on their committees, and often members who expressed interest in serving on a committee were never contacted regarding their interest. As a result, the board approved a new policy that will require each committee chair to determine the optimal size of their committee and type of members they need to meet their needs. Chairs will also determine a fair and transparent election or selection process. Members will serve on committees for 2 twoyear terms and during the open call for nominations to the board there will now be an open call for nominations for all open seats on committees. Nominations for committee positions will be sent to each committee chair to elect nominees.

The Board of Directors and the Executive Director will regularly evaluate and refine these new processes and procedures for improving NAPCRG's leadership capacity, and every effort will be made to identify opportunities to further the mission of creating an environment for all members that is nurturing, informative and inspiring.

Tom Vansagbi, $\mathrm{PbD}$

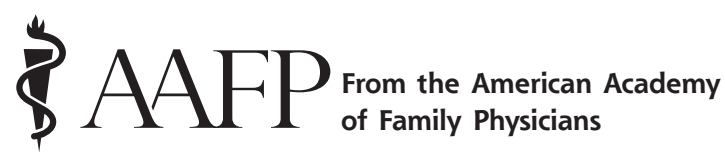

Ann Fam Med 2015;13:390-391. doi: 10.1370/afm.1825.

\section{FAMILY PHYSICIAN SALARIES UP, BUT STILL TRAIL THOSE OF SUBSPECIALISTS}

Family physicians are earning more than they did last year, with salaries that are growing faster than those for most other specialists, according to an annual survey on physician compensation. Still, the income gap between family physicians and other specialists remains wide.
On average, primary care physicians overall-and family physicians, specifically-earn $\$ 195,000$ annually, compared with $\$ 284,000$ for physicians in other specialties, the 2015 Medscape Physician Compensation Report (http://www.medscape.com) found. Pediatricians were the only specialty with a lower average salary, at $\$ 189,000$ per year. However, salaries for family physicians rose $10 \%$ between 2014 and 2015, the fifth-highest rate of increase for any specialty.

Nearly 20,000 physicians participated in the survey, which was conducted from December 30, 2014, to March 11, 2015. Of the participating physicians, family physicians and internists made up the highest volume of respondents, with each specialty comprising $12 \%$ of total respondents.

\section{Need for Value-based Compensation}

"The survey demonstrates that the importance of family medicine continues to be undervalued by the health care system," said AAFP President Robert Wergin, MD, of Milford, Nebraska. "There is hope that with passage of the MACRA (Medicare Access and CHIP [Children's Health Insurance Program] Reauthorization Act) legislation, there will be a movement away from the volume-based, fee-for-service world that is focused on acute illness and episodic care to a payment system that is value-based, and this will improve the compensation and value of family physicians."

As it stands, $47 \%$ of primary care physicians think they are compensated fairly, compared with $50 \%$ of other specialists.

It is worth noting that a physician's practice situation exerts a significant influence on annual compensation. Primary care physicians who are employed earn an average of $\$ 189,000$ annually compared with $\$ 212,000$ for self-employed physicians.

In addition, family medicine ranks sixth among specialties in employing the highest percentage of female physicians, at $35 \%$. Unfortunately, however, the gender-based income gap in medicine continues, with male physicians across all specialties earning, on average, $\$ 55,500$ more than female physicians.

"There is a disparity in our profession, and as an Academy, we have to keep advocating for equal pay for equal work," Wergin said. "We're behind, and not just in family medicine."

\section{Focus on Other Practice Issues}

The survey covered much more than salary issues, also focusing on hours spent with patients and overall career satisfaction. Several questions focused specifically on primary care, including family medicine.

For example, $34 \%$ of family physicians said they spend between 13 and 16 minutes with each patient, 